\title{
Osteoporosis and adrenal incidentaloma: To be or not to be?
}

\author{
Florica SANDRU ${ }^{1,2}$, Mihai Cristian DUMITRASCU ${ }^{2,3}$, Simona Elena ALBU ${ }^{2,3}$, \\ Mara CARSOTE ${ }^{2,4}$, Ana VALEA ${ }^{5,6}$ \\ ${ }^{1}$ Elias Emergency University Hospital, Bucharest, Romania \\ 2 "Carol Davila" University of Medicine and Pharmacy, Bucharest, Romania \\ ${ }^{3}$ Emergency University Hospital, Bucharest, Romania \\ 4 "C.I. Parhon" National Institute of Endocrinology, Bucharest, Romania \\ ${ }^{5}$ Clinical County Hospital, Cluj-Napoca, Romania \\ 6 "Iuliu Hatieganu” University of Medicine and Pharmacy, Cluj-Napoca, Romania
}

\begin{abstract}
Introduction. Adrenal incidentaloma is a more frequent diagnosis during the last decades since the relative access to abdominal ultrasound, computed tomography or magnetic resonance imagery is higher.

Aim. Our aim is to focus on the relationship between bone status (BS) in patients diagnosed and confirmed with adrenal incidentaloma.

Method. This is a mini-review of the literature. Most of the included papers were published during the last 5 years. The main research tool is PubMed database.

General data. BS is affected in adrenal incidentaloma mainly through persistent autonomous cortisol production which is called (even lately the term is not encouraged) "subclinical Cushing's syndrome" with a prevalence of 0.2 up to $2 \%$ in unselected series of adult people. TBS (Trabecular Bone Score) in both men and women is negatively correlated with plasma cortisol after $1 \mathrm{mg}$ dexamethasone suppression test. There is $2.2 \%$ decrease of TBS if subclinical Cushing's syndrome is confirmed opposite to clear non-functioning pattern of the adrenal incidenaloma. Bone mineral density based on DXA at central sites (lumbar spine and femoral neck) was similar between the subject with unilateral and bilateral incidentaloma. The presence of subliclinical hypercortisolism is positively correlated with a higher risk of osteoporosis and fragility fractures Recently the term of "high risk" patients with adrenal incidentaloma has been introduced in order to describe the subgroup with autonomous cortisol secretion that has an increased risk of cardiovascular morbidities, infections and fractures (even independently of DXA - bone mineral density.

Conclusion. The main contributor to BS, as well as to the cardiometabolic damage, remains the autonomous cortisol secretion in adrenal incidentaloma with a potential improvement after adrenalectomy and without a specific anti-osteoporotic medication in this particular situation.
\end{abstract}

Keywords: adrenal tumour, osteoporosis, fracture, cortisol

\author{
Abbreviations \\ $\mathrm{BS}=$ bone status \\ DXA = Dual-Energy X-Ray Absorptiometry \\ TBS = Trabecular Bone Score
}




\section{INTRODUCTION}

Adrenal incidentaloma is a more frequent diagnosis during the last decades since the relative access to abdominal ultrasound, computed tomography or magnetic resonance imagery is higher $(1,2)$ (Figure 1). The incidence is expected to rise due to technological progress $(1,2)$. The finding has an age-dependent pattern $(2,3)$. The diagnosis actually includes two aspects: one is the radiological or imaging detection through any of the mentioned procedures, and the other aspect is related to the clinical and endocrine assessment that finally decides that the incidental tumour is a "true" incidentaloma meaning that overall there is a negative secretor profile and the route to its detection was accidental $(4,5)$. However, a possible or a probable autonomous cortisol production is included and thus some long term complications might be expected, ignored or considered "idiopathic" or just "age-related" as seen in subjects diagnosed with high blood pressure, hyperlipemia and osteoporosis especially in menopausal women $(1,5,6)$. The lesion typically has at least 10 millimetres $(\mathrm{mm})(6)$. The hormonal workup includes: morning plasma cortisol and ACTH, cortisol circadian rhythm, salivary plasma cortisol, 24-hour urinary free cortisol, plasma/urinary metanephrines and normetanephrines, adrenal androgens, aldosteron and aldosteron/renin ratio (6). Some drugs if they are co-administered might alter the results of the assays and a level of awareness is necessary among practitioners $(1,6)$.

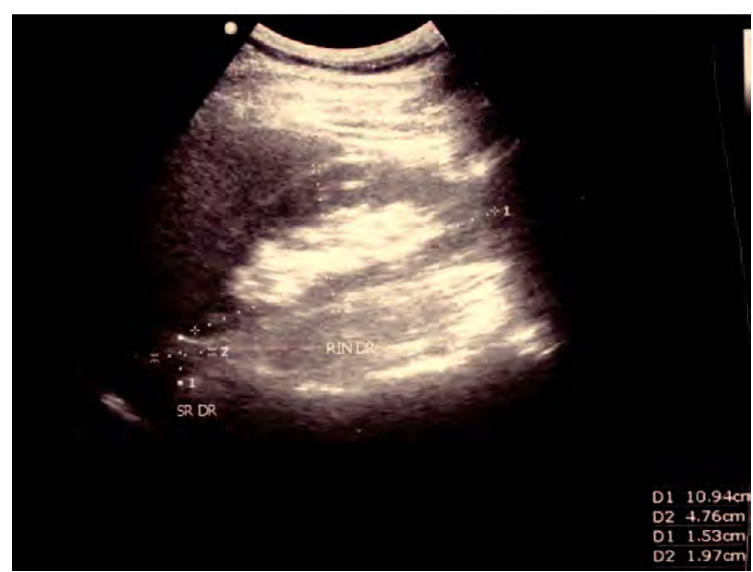

FIGURE 1. Abdominal ultrasound on a menopausal woman showing a right adrenal tumour of 1.53 by 1.97 $\mathrm{cm}$ (an adrenal incidentaloma)

\section{AIM}

Our aim is to focus on the relationship between bone status especially osteoporosis in patients diagnosed and confirmed with adrenal incidentalo- ma after both radiological and endocrine evaluation.

\section{MATERIAL AND METHOD}

This is a mini-review of the literature. Most of the included papers were published during the last 5 years. The main research tool is PubMed database. The general data is grouped around several key points based on a clinical approach. A number of 33 papers have been included based on clinical relevance.

\section{GENERAL DATA}

\section{Adrenal incidentaloma}

The prevalence of adrenal incidentaloma is up to $3 \%$ based on unselected series of general population (4). The percent increases to $10 \%$ after the age of 70 years (4). The radiological (unselected speaking about endocrine pattern) includes: $80 \%$ of cases are adenomas derived by adrenal cortex with benign features displaying a completely negative endocrine profile (most of them) or autonomous cortisol secretion (between $10 \%$ and $50 \%$ ) or aldosterone excessive secretion (between $1 \%$ and $10 \%$ ) (4). The excess of pure adrenal androgens is extremely rare in cases without other secretions and these cases are not usually asymptomatically at presentation so they can barely fit to the diagnosis of adrenal incidentaloma $(7,8)$. The cortisol excess (even subclinical) is more frequent in subjects with bone loss or vertebral fractures $(4,9)$.

\section{Autonomous secretion of cortisol}

The persistent cortisol secretion, even mild, is autonomous and it underlines the typical long term complications of subclinical hypercortisolism which is found positive in one third up to half of the cases confirmed with adrenal incidentaloma (10). The main clinical aspects are the fact that classical phenotype of Cuhsing's syndrome is lacking $(10,11)$. However, morbidities like obesity, type 2 diabetes mellitus or impaired glucose tolerance, hyperlipemia, osteoporosis, and high blood pressure are typically found after the age of 50 years and they may be considered as age-related, but not necessarily incidentaloma- related (10). There is a fine line between establishing the real cause of these conditions and their follow-up may show an unexplained worsening thus most probably tumor-related, while adrenalectomy may associate an improvement of the parameters so the connec- 
tion with the tumor endocrine profile is confirmed $(10,12)$.

\section{Glucocorticoid osteoporosis}

Despite the fact that typical Cushing's syndrome is not found, chronic cortisol exposure affects the bone and glucocorticoid osteoporosis is the most common form of secondary type $(13,14,15)$. The source of cortisol may be endogenous as adrenal and pituitary tumour derived or exogenous since glucocorticoids are used in many rheumatologic, dermatological, lung, etc conditions $(13,14,15)$. Regardless the origin of the glucocorticoids excess, the mechanisms of bone loss includes reduced bone formation and increased bone resorption which is time-dependent as well as dose-dependent $(16,17,18)$. DXA (Dual-Energy X-Ray Absorptiometry) is a useful tool to evaluate the bone loss but sometimes it underestimates the fracture risk (16).

\section{Bone status (BS)}

BS is affected in adrenal incidentaloma mainly through persistent autonomous cortisol production which is called (even lately the term is not encouraged) "subclinical Cushing's syndrome" with a prevalence of 0.2 up to $2 \%$ in unselected series of adult people (19). One study published in 2018 by Kim BJ et al. showed that TBS (Trabecular Bone Score) in both men and women is negatively correlated with plasma cortisol after the use of $1 \mathrm{mg}$ dexamethasone suppression test (20). Moreover, there is $2.2 \%$ decrease of TBS if subclinical Cushing's syndrome is confirmed opposite to clear non-functioning pattern of the adrenal incidenaloma (20). TBS have a tendency to correlate with the values of plasma cortisol after mentioned suppression test (20). The statistical quality of the data is higher in women (20).

Another study on 152 subjects with adrenal incidentaloma ( $2 / 3$ had unilateral lesions and $1 / 3$ had bilateral lesions) showed that among them $20 \%$ had subclinical Cushing's syndrome (more frequent in bilateral tumours) but the bone mineral density based on DXA at central sites (lumbar spine and femoral neck) was similar between the subgroups (21). Another meta-analysis based on 6 studies including 1239 patients with adrenal incidentaloma showed that metabolic complications as well as osteoporosis do not differ if the incidentaloma is uni or bilateral (22). On the other hand, the presence of subliclinical hypercortisolism is positively correlated with a higher risk of osteoporosis and fragility fractures versus patients with negative secretor profile and adrenal incidentaloma (23). Recently the term of "high risk" patients with adrenal incidentaloma has been introduced in order to describe the subgroup with autonomous cortisol secretion that has an increased risk of cardiovascular morbidities, infections and fractures (even independently of DXA - bone mineral density (24).

\section{DISCUSSION}

The influence of BS in adrenal incidentaloma is also directly due to the presence of obesity, type 2 diabetes mellitus and hyperlipemia as potential contributors to increased risk of vertebral fractures, not necessarily through hypercortisolism $(25,26)$. Also, the data regarding the non-cortisol hormones of the adrenal cortex is controversial. The lesions like lipomas and cysts are irrelevant to BS (27). The effect of aldosterone excces over BS is less understood up to present time (3). It seems that clear aldosteron overproduction causes a deterioration of bone microarchitecture as shown by low TBS (28). Some authors suggested that a higher activity of the sympathetic activity induces skeleton status damage (29). Other secondary causes of osteoporosis related to concomitant endocrine tumours with overproduction of different hormones like pituitary adenomas including prolactionomas are described in addition to adrenal incidentalomas but this is a rare event $(30,31)$.

The main contributor to $\mathrm{BS}$, as well as to the cardiometabolic damage, remains however the autonomous cortisol secretion in adrenal incidentaloma with a potential improvement after adrenalectomy and without a specific anti-osteoporotic medication in this particular situation $(32,33)$.

\section{CONCLUSION}

Adrenal incidentaloma and osteoporosis, respective fragility fractures are still an open topic; up to this moment the correlation is based on autonomous cortisol secretion as main contributor.

Conflict of interest: none declared Financial support: none declared 


\section{REFERENCES}

1. Fassnacht $M$, Arlt $W$, Bancos I, Dralle $H$, Newell-Price J, Sahdev A, Tabarin A, Terzolo M, Tsagarakis S, Dekkers OM. Management of adrenal incidentalomas: European Society of Endocrinology Clinical Practice Guideline in collaboration with the European Network for the Study of Adrenal Tumors. Eur J Endocrinol. 2016 Aug; 175(2):G1-G34.

2. Gheorghisan-Galateanu AA, Carsote M, Valea A. Incidentaloma: From general practice to specific endocrine frame. J Pak Med Assoc. 2017.67(6):917-922.

3. Gheorghiu M, Hortopan D, Dumitrascu A, Caragheorgheopol A, Stefanescu A, Trifanescu R, Niculescu D, Baciu I, Carsote M, Poiana C, Badiu C, Coculescu M. Age-related endocrine tumors: Nonfunctioning adrenal tumors as compared to pituitary adenomas. Acta Endocrinologica, 2009; V(3):371-384.

4. Altieri $B$, Muscogiuri $G$, Paschou SA, Vryonidou A, Della Casa S, Pontecorvi A, Fassnacht M, Ronchi CL, Newell-Price J. Adrenocortical incidentalomas and bone: From molecular insights to clinical perspectives. Endocrine. 2018 Dec; 62(3):506-516.

5. Lee JM, Kim MK, Ko SH, Koh JM, Kim BY, Kim SW, Kim SK, Kim HJ, Ryu OH, Park J, Lim JS, Kim SY, Shong YK, Yoo SJ; Korean Endocrine Society, Committee for Clinical Practice Guidelines. Clinical Guidelines for the Management of Adrenal Incidentaloma. Endocrinol Metab (Seoul). 2017 Jun; 32(2):200-218

6. Cyrańska-Chyrek E, Grzymisławska M, Ruchała M. Diagnostic pitfalls of adrenal incidentaloma. Endokrynol Pol. 2017; 68(3):360-377.

7. Karimi F, Dehghanian A, Fallahi M, Dalfardi B. Pure Androgen-Secreting Adrenocortical Carcinoma Presenting with Hypoglycemia. Arch Iran Med. 2019 Sep 1;22(9):527-530.

8. Panchani R, Goyal A, Varma T, Gupta N, Tripathi S, Kumar S. Adrenal incidentalomas: A collection of six interesting cases and brief review of literature. Indian J Endocrinol Metab. 2012 Dec; 16(Suppl 2):S378-81.

9. Carsote M, Ghemigian A, Valea A, Dumitrascu A, Chirita C, Poiana C. Sublinical Cushing's syndrome with bilateral adrenal tumours in a patient with gallbladder multiple stone: therapeutical options. Ars Medica Tomitana. 2015; 3(21);124-127.

10. Debono M, Newell-Price J. Subclinical hypercortisolism in adrenal incidentaloma. Curr Opin Endocrinol Diabetes Obes. 2015 Jun; 22(3):185-92.
11. Poiana C, Chirita C, Carsote M, Hortopan D, loachim D, Corneci CM, Stanescu B. Adrenal and Pituitary Incidentalomas in a Case of Cushing's Syndrome. Chirurgia 2013;6(108):886-891.

12. Paduraru DN, Nica $A$, Carsote $M$, Valea $A$. Adrenalectomy for Cushing's syndrome: do's and don'ts. Journal of Medicine and Life. 2016; 4(9):334-341.

13. Adami G, Saag KG. Glucocorticoid-induced osteoporosis update. Curr Opin Rheumatol. 2019 Jul; 31(4):388-393.

14. Adami G, Rahn EJ, Saag KG. Glucocorticoid-induced osteoporosis: from clinical trials to clinical practice. Ther Adv Musculoskelet Dis. 2019 Sep 20; 11:1759720X19876468.

15. Buckley L, Humphrey MB GlucocorticoidInduced Osteoporosis. N Engl J Med. 2018 Dec 27; 379(26):2547-2556.

16. Adami G, Saag KG. Glucocorticoid-induced osteoporosis: 2019 concise clinical review. Osteoporos Int. 2019 Jun;30(6):1145-1156.

17. Colangelo L, Biamonte F, Pepe J, Cipriani C, Minisola S. Understanding and managing secondary osteoporosis. Expert Rev Endocrinol Metab. 2019 Mar; 14(2):111-122.

18. Lane NE. Glucocorticoid-Induced Osteoporosis: New Insights into the Pathophysiology and Treatments. Curr Osteoporos Rep. 2019 Feb;17(1):1-7. doi: 10.1007/s11914-019-00498-x.

19. Chiodini I, Albani A, Ambrogio AG, Campo M, De Martino MC, Marcelli G, Morelli V, Zampetti B, Colao A, Pivonello R; ABC Group. Six controversial issues on subclinical Cushing's syndrome. Endocrine. 2017 May; 56(2):262-266.

20. Kim BJ, Kwak MK, Ahn SH, Kim JS, Lee $\mathrm{SH}$, Koh JM. The association of cortisol and adrenal androgen with trabecular bone score in patients with adrenal incidentaloma with and without autonomous cortisol secretion. Osteoporos Int. 2018 Oct; 29(10):2299-2307.

21. Ognjanović $S$, Macut $D$, Petakov M, Elezović Kovačević $V$, Isailović $T$, Bozić Antić I, llić D, Popović B, Bogavac T, Pekmezović T, Damjanović S. The Occurrence of Subclinical Hypercortisolism and Osteoporosis in Patients with Incidentally Discovered Unilateral and Bilateral Adrenal Tumors. J Med Biochem. 2016 Nov 2; 35(4):401-409.

22. Paschou SA, Kandaraki E, Dimitropoulou F, Goulis DG, Vryonidou A. Subclinical Cushing's syndrome in patients with bilateral compared to unilateral adrenal incidentalomas: A systematic review and meta-analysis. Endocrine. 2016 Feb; 51(2):225-35.

23. Di Dalmazi G, Vicennati V, Rinaldi $E$, Morselli-Labate AM, Giampalma E, Mosconi C, Pagotto U, Pasquali R. Progressively increased patterns of subclinical cortisol hypersecretion in adrenal incidentalomas differently predict major metabolic and cardiovascular outcomes: A large cross-sectional study. Eur J Endocrinol. 2012 Apr;166(4):669-77.

24. Di Dalmazi G. Adrenal Incidentaloma: Picking out the High-Risk Patients. Exp Clin Endocrinol Diabetes. 2019 Feb; 127(2-03):178-184.

25. Poiana C, V.Radoi, Carsote M, Bilezekian J. New Clues that May Link Osteoporosis to the Circulating Lipid Profile. Bone Research 2013;1(3):260-266.

26. Radu L, Carsote M, GheorghisanGalateanu AA, Preda SA, Calborean V, Stanescu R, Gheorman V, Albulescu DM. Blood Parathyrin and Mineral Metabolism Dynamics. A clinical analyze. Rev.Chim. (Bucharest). 2018;69(10):2754-2758.

27. Poiana C, Carsote M, Chirita C, Terzea D, Paun S, Beuran M. Giant adrenal cyst: case study, J Med Life 2010;3(3):308-313.

28. Kim BJ, Kwak MK, Ahn SH, Kim H, Lee SH, Koh JM Lower Trabecular Bone Score in Patients With Primary Aldosteronism: Human Skeletal Deterioration by Aldosterone Excess. J Clin Endocrinol Metab. 2018 Feb 1;103(2):615-621.

29. Kim BJ, Kwak MK, Kim JS, Lee SH, Koh JM. Higher sympathetic activity as a risk factor for skeletal deterioration in pheochromocytoma. Bone. 2018 Nov; 116:1-7.

30. Poiana C, Chirita C, Carsote M, Hortopan D, Goldstein A. Galactocele and prolactinoma - A pathogenic association? Maturitas. 2009; 62(1):98-102.

31. Carsote M, Chirita C, Dumitrascu A, Fica S, Poiana C. Pituitary incidentalomas-How often is too often? Journal of Medicine and Life, 2009;2(1):92-97.

32. Araujo-Castro M, Sampedro Núñez MA, Marazuela M. Autonomous cortisol secretion in adrenal incidentalomas. Endocrine. 2019 Apr;64(1):1-13.

33. Araujo-Castro M, Robles Lázaro C, Parra Ramírez $\mathrm{P}$, Cuesta Hernández M, Sampedro Núñez MA, Marazuela M. Cardiometabolic profile of non-functioning and autonomous cortisol-secreting adrenal incidentalomas. Is the cardiometabolic risk similar or are there differences? Endocrine. 2019 Dec;66(3):650-659. 